\title{
Effects of captopril and enalapril on renal function in elderly patients with chronic heart failure
}

\author{
CA Haffner, MJ Kendall, AD Struthers, A Bridges, DJ Stott
}

\begin{abstract}
Summary
Objective: To compare the effects on renal function of captopril and enalapril in elderly patients with chronic heart failure.

Design: A multi-centre double-blind parallel-group comparison of the two angiotensin-converting enzyme (ACE) inhibitors, captopril (12.5 $\mathrm{mg}$ bid) and enalapril ( $2.5 \mathrm{mg}$ bid).

Subjects: 80 elderly patients with chronic heart failure (41 in the captopril group, 39 in the enalapril group).

Main outcome measures: The blood pressure and pulse rate response to the first dose of ACE inhibitor was assessed in all patients. Glomerular filtration rate (GFR) was measured radioisotopically by 99mTcDTPA or 51CrEDTA clearance after three and six months of each treatment. Subgroups were assessed for effective renal plasma flow (33 patients), exercise tolerance ( 25 patients) and by a symptom-oriented questionnaire (45 patients).
\end{abstract}

Department of Health Care for the Elderly, Hayward Building, Selly Oak Hospital, Selly Oak, West Midlands, UK

CA Haffner

Department of Medicine, Queen Elizabeth Hospital, Edgbaston, Birmingham 15, UK MJ Kendall

Department of Pharmacology and Clinical Pharmacology, Ninewells Hospital and Medical School, Dundee, DD1 9SY, UK AD Struthers A Bridges

Department of Geriatric Medicine, Southern General Hospital, Glasgow, G51 4TF, UK

DJ Stott

Correspondence to Dr MJ Kendall

Accepted 6 December 1994 was noticed. There was no significant difference between the two treatments in the mean baseline GFR or in changes from baseline at three and six months (captopril mean baseline GFR $49.6 \mathrm{ml}$ $\min ^{-1} 1.76 \mathrm{~m}^{-2}$, enalapril $54.7 \mathrm{ml} \mathrm{min}^{-1}$ $1.76 \mathrm{~m}^{-2}$; mean change $(95 \%$ confidence interval) at three months captopril $12 \mathrm{ml} \mathrm{min}^{-1}(+3.0,+21.0)$, enalapril $-2 \mathrm{ml} \mathrm{min}{ }^{-1}(-13.0 ;+9.0)$; mean change at six months, captopril $3.7 \mathrm{ml} \mathrm{min}^{-1}$ $\left(-6.7\right.$; + 14.2), enalapril $-6.0 \mathrm{ml} \mathrm{min}^{-1}$ $(-21.0 ;+9.4)$. Significantly more patients given captopril had an improvement in GFR during the study period $(26 / 31 \mathrm{com}-$ pared with 20/31 enalapril-treated patients at three months, $p=0.0096$, and $23 / 30$ compared with $15 / 27$ at six months, $p=0.021)$. There were no significant changes in effective renal plasma flow. Three patients treated with enalapril developed symptomatic hypotension within three days of starting treatment. Quality of life questionnaires revealed more gastrointestinal symptoms in the enalapril group $(p=0.039)$.

Conclusions: Captopril seems marginally preferable to enalapril in the treatment of chronic heart failure in elderly patients.
Results: No serious adverse effect on GFR
Keywords: ACE-inhibitors, renal function, elderly, enalapril, captopril

\section{Introduction}

Cardiac failure is a common clinical problem and the majority of patients with heart failure are more than 65 years old..$^{1-4}$ Better treatment of heart failure in the elderly could therefore make a great impact (box 1).

Over the last decade, angiotensionconverting enzyme (ACE) inhibitors have established themselves in the treatment of heart failure. Controlled trials ${ }^{5-7}$ show symptomatic improvement and increased exercise tolerance on chronic treatment (more than three months). The CONSENSUS study compared enalapril with placebo and demonstrated a reduction in one-year mortality from $52 \%$ to $31 \% .^{8}$ The SOLVD study showed a $16 \%$ reduction in mortality at one year among enalapril-treated patients with less severe heart failure associated with systolic dysfunction. ${ }^{9}$ The SAVE study ${ }^{10}$ and the AIRE study ${ }^{11}$ established that the benefits of ACE-inhibitor therapy also apply to post-myocardial infarction patients with left ventricular dysfunction who were at risk of developing heart failure. These are important findings for a condition with such a poor prognosis.

Many of the studies cited above included some patients over 65 years of age but few have considered ACE-inhibitor therapy specifically in elderly people. ${ }^{12-17}$ The age of patients participating in large multicentre trials is lower than patients with heart failure in the community. There is some evidence that ACE inhibitors have a worse side-effect profile in the elderly ${ }^{17}$ and the fear of hypotension and renal dysfunction in particular may hinder the use of

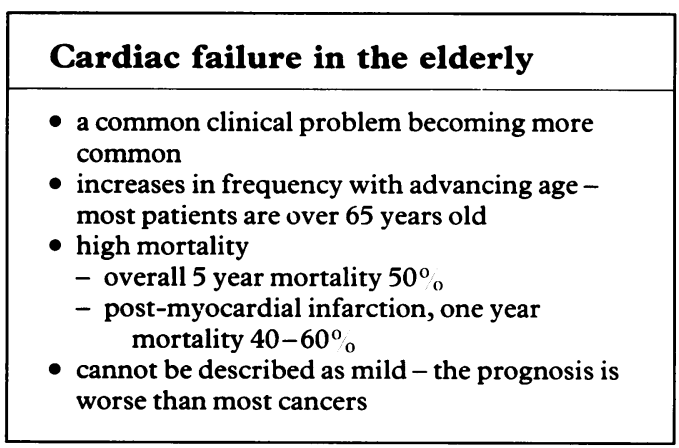


ACE-inhibitor therapy in elderly heart failure patients. For these reasons we only studied heart failure patients who were over 65 years of age.

Two studies comparing short-acting and long-acting ACE inhibitors suggested that the former cause less renal dysfunction. ${ }^{18,19}$ It may be that a short-acting ACE inhibitor allows restoration of some angiotensin II at the end of each dose interval and that this protects the glomerular filtration rate (GFR).$^{20}$ Our aim was therefore to compare the effects of low doses of captopril and enalapril on renal function in a group of elderly people with chronic cardiac failure.

\section{Subjects and methods}

This was a six-month double-blind, group comparative study of captopril $(12.5 \mathrm{mg}$, bid) versus enalapril ( $2.5 \mathrm{mg}$ bid). Six centres were involved in recruitment. Inclusion and exclusion criteria for the study population are shown in box 2 .

At their first visit, patients were assessed for their suitability to join the study and after full explanation gave their written consent. The study was approved by the ethics committees of all centres involved. Baseline assessments included: haemodynamic measurements (lying and standing blood pressure and pulse); blood tests (urea, creatinine and electrolytes, liver function tests, glucose, full blood count); standard 12-lead electrocardiogram (ECG); postero-anterior chest X-ray; exercise test; and administration of a symptom-oriented questionnaire.

There followed a run-in period of up to two weeks when each patient took a placebo capsule twice daily. A second set of baseline assessments was performed within a week of the first visit and this included measurement of GFR. This was measured using a single injection, three blood sample radio isotope clearance technique, ${ }^{21}$ the radio isotope being 99m TcDTPA at one centre and 51CrEDTA at the other centres. In addition, iodohippurate measurement of effective renal plasma flow was performed by three centres.

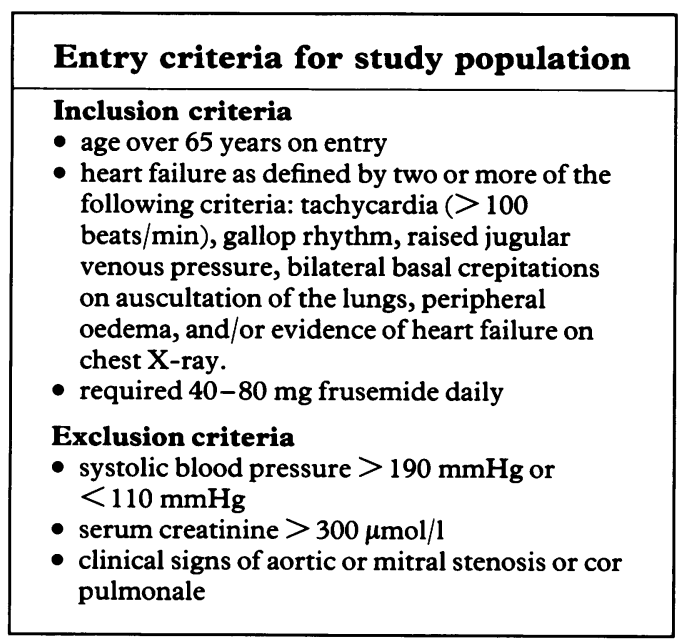

Box 2
The first dose of ACE inhibitor was administered the day after a reduction of dose of frusemide to $40 \mathrm{mg}$ daily if the dose had previously been $80 \mathrm{mg}$ daily. Semi-supine blood pressure and pulse rate were measured every 30 minutes for six hours following the first dose.

Patients were reviewed one week following initiation of therapy when haemodynamic measurements, blood tests and the questionnaire were repeated. Further complete assessments, including measurement of GFR and effective renal plasma flow, were done at three and six months. In addition to the formal assessments, patients were visited monthly to deliver supplies of medications and assess compliance (by tablet count).

Patients were withdrawn from the study if any of the following were observed: worsening cardiac function, serious adverse event, death, poor compliance (more than $80 \%$ tablets must have been consumed for the patient to remain in the study), symptomatic hypotension, development of an exclusion criterion, inclusion criteria later found to be inadequate, or if they were lost to follow-up.

The walking test was performed in 25 patients from one centre, by asking them to walk an individually selected distance and the time taken to perform this was measured using a stopwatch. This had previously been validated by a pilot study in 10 fit and 20 frail elderly people.

In one centre an interviewer administered a symptom-oriented questionnaire to assess quality of life and minor adverse effects. This had also been validated by a pilot study in $10 \mathrm{fit}$ and 20 frail elderly people.

The distribution of all the variables studied were assessed for normality and differences between the treatment groups were tested by analysis of variance with treatment and centre as factors or by using permutation tests ${ }^{22}$ as appropriate. Formal comparisons between the treatment groups for symptom profiles and adverse events were carried out using either chi-square or Fisher's exact test. Confidence intervals were two-tailed. Differences were accepted as statistically significant at the 5\% level of probability. Measurements for GFR were corrected for body surface area using the standard equation.

\section{Results}

A total of 96 patients from six centres entered the placebo run-in phase of the study; 16 were ineligible, thus 80 patients were randomised to active treatment. The characteristics of the patients studied are shown in table 1 . There were no significant differences between the two treatment groups in any of the baseline features. A further 24 patients were withdrawn during the study for the reasons shown in table 2. They were included in the analysis until the point at which they were withdrawn from the study.

GFR

Measurements of GFR are summarised in table 
Table 1 Population characteristics at start of study (mean and range or absolute numbers)

\begin{tabular}{lll}
\hline & Captopril group & Enalapril group \\
\hline No patients & 41 & 39 \\
Age (years) & $77(66-93)$ & $75.3(65-93)$ \\
Height (cm) & $163.2(154-184)$ & $163.0(147-180)$ \\
Weight (kg) & $65.1(40.0-88.0)$ & $67.1(48.1-96.6)$ \\
Abnormal ECG` & 36 & 33 \\
Abnormal chest X-ray & 38 & 36 \\
Clinical signs: & 16 & \\
tachycardia & 27 & 21 \\
gallop rhythm & 13 & 31 \\
raised jugular venous pressure & 31 & 17 \\
pulmonary oedema & 24 & 27 \\
oedema & $88.9(83.8-94.0)$ & $90.9(84.5-97.3)$ \\
Pulse & & 19 \\
Blood pressure (mmHg) & $149(141-157)$ & $140(134-147)$ \\
lying: systolic & $81(75-86)$ & $82(78-86)$ \\
standing: systolic & $149(142-155)$ & $136(130-141)$ \\
$\quad$ diastolic & $88(78-87)$ & $80(76-84)$ \\
\hline
\end{tabular}

*previous myocardial infarction, left or right bundle branch block, arrhythmia, left ventricular hypertrophy or left axis deviation

Table 2 Reasons for withdrawal (number of patients)

\begin{tabular}{lcc}
\hline Reason & $\begin{array}{l}\text { Captopril } \\
\text { group }\end{array}$ & $\begin{array}{l}\text { Enalapril } \\
\text { group }\end{array}$ \\
\hline Death (sudden) & $3(1)$ & $3(3)$ \\
Ineffective & 2 & 1 \\
Poor compliance & 1 & 1 \\
Symptomatic hypotension & 0 & 4 \\
Other adverse event & 5 & 0 \\
On non-permitted drug & 1 & 0 \\
Anaemia & 1 & 0 \\
Cardiac surgery & 0 & 1 \\
Proteinuria & 0 & 1 \\
Renal impairment & 0 & 1 \\
Patient request & 0 & 1 \\
Cough & 0 & 1 \\
Total events & 13 & 14 \\
\hline
\end{tabular}

NB Three patients had more than one reason for withdrawal

Table 3 GFR ( $\mathrm{ml} \mathrm{min} \mathrm{mi}^{-1} 1.76 \mathrm{~m}^{-2}$ ) (mean and confidence intervals)

\begin{tabular}{lll}
\hline & Captopril group & Enalapril group \\
\hline Baseline & $49.6(42.0-55.6)$ & $54.7(48.3-61.1)$ \\
$n$ & 41 & 39 \\
12 weeks & $55.5(48.0-63.0)$ & $51.7(45.1-57.3)$ \\
$n$ & 33 & 30 \\
24 weeks & $53.3(45.7-60.9)$ & $50.6(41.9-59.3)$ \\
$n$ & 31 & 25 \\
\hline
\end{tabular}

3 for the entire intention-to-treat population. The mean baseline GFR for those treated with captopril was $49.6 \mathrm{ml} \mathrm{min}^{-1} 1.76 \mathrm{~m}^{-2}$ (range $16.0-129.3)$ and $54.7 \mathrm{ml} \mathrm{min}^{-1} 1.76 \mathrm{~m}^{-2}$ (range 17.5-109.0) for the enalapril group. The mean change from baseline values after three months was $6 \mathrm{ml} \mathrm{min}^{-1}$ for the captopril group and $-3.0 \mathrm{ml} \mathrm{min}^{-1}$ for the enalapril group. The corresponding values for six months were $3.7 \mathrm{ml} \mathrm{min}^{-1}(-6.7 ;+14.2)$ and $-6.0 \mathrm{ml} \mathrm{min}^{-1}(-21.0 ;+9.4)$, respectively.
None of these values were statistically significant within or between the treatment groups, though the trend was for GFR to increase in the captopril group and to decrease in the enalapril group.

Proportions of patients showing a more than $10 \%$ change in GFR from baseline are shown in figure 1. More patients in the captopril group showed an increase in GFR; $26 / 31$ patients showed an improvement of more than $10 \%$ compared with $20 / 31$ in the enalapril group (permutation test $\mathrm{p}=\mathbf{0 . 0 0 9 6}$ at three months) while at six months the figures were $23 / 30$ captopril-treated patients compared with $15 / 27$ enalapril-treated patients, $p=0.021$. There was no significant change in renal blood flow induced by treatment nor any difference between treatments. Only two patients were withdrawn as a result of adverse effects on renal function; one had proteinuria at six months, the other had a marked deterioration in renal function related to a chest infection at six months. Both patients were taking enalapril; the adverse renal effects recovered on stopping the drug.

\section{BLOOD PRESSURE}

Figure 2 shows the time course of the mean changes in systolic blood pressure following the first dose of ACE-inhibitor. Patients in the captopril group showed substantial reductions in systolic blood pressure between 30 and 180 minutes after dosing, whereas patients in the enalapril group showed a similar fall at between 210 to 330 minutes after dosing. The percentages of patients showing a fall in systolic blood pressure of more than $20 \mathrm{mmHg}$ are shown in table 4 . There were no complaints of dizziness
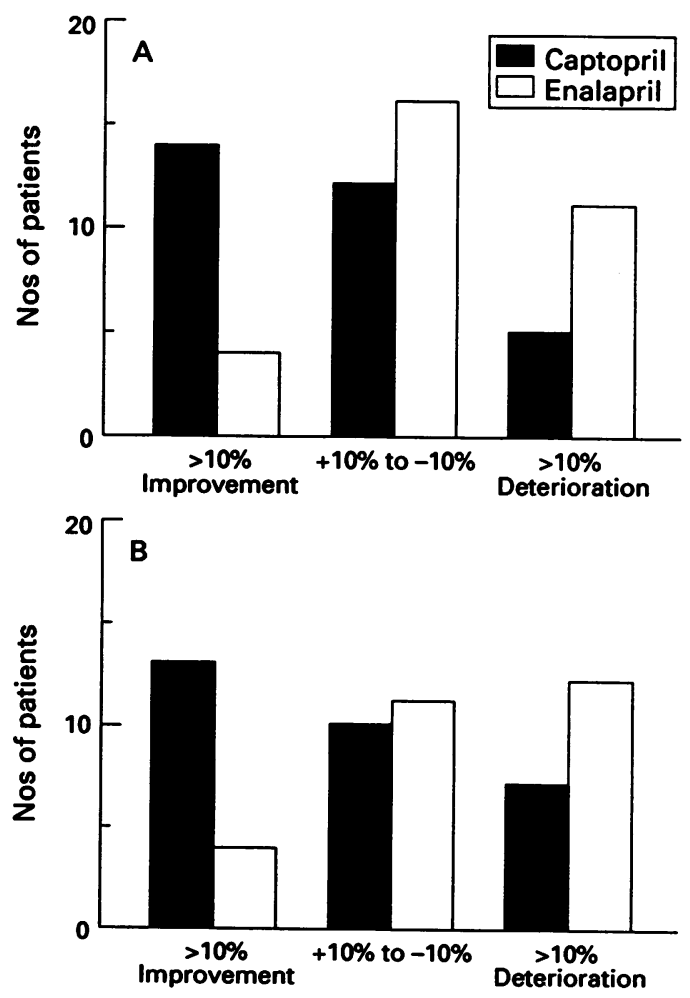

Figure 1 Percentage change in GFR from baseline (A) at 12 weeks, (B) at 24 weeks 


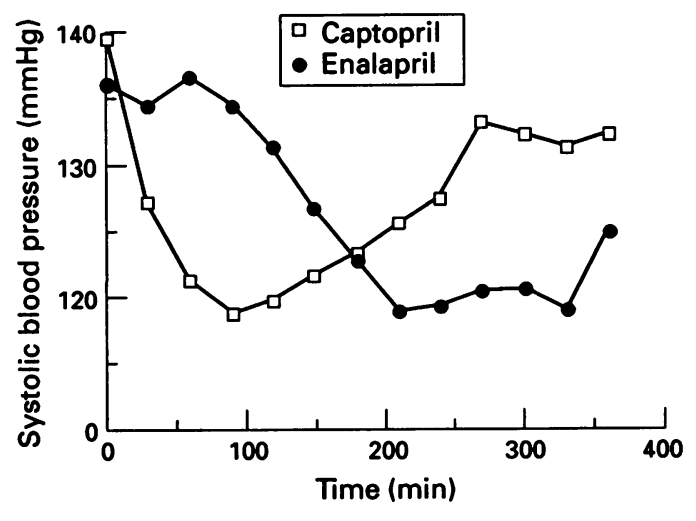

Figure 2 Systolic blood pressure after first dose of ACE inhibitor

Table 4 Number (percentage) of patients with fall in systolic blood pressure $>20 \mathrm{mmHg}$ after first dose of ACE inhibitor

\begin{tabular}{lll}
\hline Time (min) & Captopril group & Enalapril group \\
\hline 30 & $14(34)$ & $6(15)$ \\
60 & $20(48)$ & $4(10)^{\star}$ \\
90 & $22(53)$ & $5(12)^{\star}$ \\
120 & $19(46)$ & $5(12)^{\star}$ \\
150 & $22(53)$ & $10(25)$ \\
180 & $17(41)$ & $10(25)$ \\
210 & $14(34)$ & $16(41)$ \\
240 & $12(29)$ & $15(38)$ \\
270 & $7(21)$ & $17(43)$ \\
300 & $13(32)$ & $14(36)$ \\
330 & $10(24)$ & $18(46)$ \\
360 & $12(29)$ & $12(30)$ \\
$\mathrm{n}$ & 41 & 39 \\
\hline${ }^{\star} \mathrm{p}<0.05$ & &
\end{tabular}

despite these falls in blood pressure. No patients had a systolic blood pressure lower than $60 \mathrm{mmHg}$ during initiation of treatment and none required saline infusion. However, three patients in the enalapril group had symptomatic hypotension within three days of the first dose. Interestingly they all presented with reduced mobility rather than dizziness or syncope. Diastolic blood pressure followed a similar pattern.

\section{Biochemistry}

Biochemical parameters were compared between the two groups and within each group at each visit for patients at one centre (45 patients). No statistically significant differences were found. One patient on enalapril developed hypokalaemia (lowest value $2.9 \mathrm{mmol} / \mathrm{l})$ and one taking captopril developed hyponatraemia $\left(\mathrm{Na}^{+} 129 \mathrm{mmol} / \mathrm{l}\right)$.

\section{WALKING TESTS}

Walking tests were performed on 25 patients from one centre and revealed an improvement in both treatment groups after three months therapy $(0.43$ (SD 0.21$) \mathrm{m} / \mathrm{s}$ to 0.51 (SD 0.20 ) $\mathrm{m} / \mathrm{s}$ captopril, 0.44 (SD 0.23 ) $\mathrm{m} / \mathrm{s}$ to 0.49 (SD $0.20) \mathrm{m} / \mathrm{s}$ enalapril). A trend to further improvement at six months occurred in the captopril group $(0.54(S D 0.14) \mathrm{m} / \mathrm{s})$ but not in the enalapril group $(0.49(\mathrm{SD} 0.28) \mathrm{m} / \mathrm{s})$. None of the differences between the captopril and enalapril groups achieved statistical significance.

\section{ADVERSE EVENTS}

Adverse events leading to withdrawal of patients are listed in table 2. Twenty-four $(30 \%)$ of the 80 patients entered into the study were withdrawn after randomisation. One patient, an 82-year-old man taking captopril, was withdrawn after two months due to hypotension associated with commencement of metolazone $5 \mathrm{mg}$ daily.

Questionnaires administered by the same interviewer to 45 patients revealed a significantly greater number of gastrointestinal complaints in the enalapril group (9/14 patients compared with $2 / 18$ in the captopril group, $\mathrm{p}=0.039$ )

\section{Discussion}

ACE inhibitors are now important first-line therapy in the management of heart failure (see box). ${ }^{23}$ However, they can cause deterioration in renal function in those dependent on angiotensin II mediated efferent arteriolar vasoconstriction, such as those with heart failure or with renal artery stenosis. ${ }^{24}$ This may be particularly important in the elderly, due to the age-related decline in renal function. Activation of the renin-angiotensin system is the principal hormonal response of the kidney to a fall in renal blood flow, ${ }^{25}$ increasing local and circulating renin, angiotensin II and aldosterone. Angiotensin II maintains GFR by efferent arteriolar vasoconstriction and may have other effects on the kidney, for example, contraction of mesangial cells and a fall in glomerular surface area and permeability. ${ }^{26}$ Captopril and enalapril often initially depress GFR, especially when there is marked hypotension after the first dose. ${ }^{24}$ Packer $^{27}$ found a tendency for enalapril to cause a greater elevation in serum urea and creatinine than captopril, although the differences between the two drugs were not statistically significant.

Reducing the adverse effects of firstdose hypotension

\section{Risk factors:}

- initial low blood pressure

- severe heart failure

- high doses of diuretics

- low serum sodium

- other vasodilators

Precautions:

- omit the morning dose of diuretic (if needed, give later)

- start with low dose of ACE inhibitor

- administer to patient who is and remains sitting for 2-3 h (bladder emptied first)

- patient should not be alone - if they become hypotensive lie them down and elevate legs

Note: some newer longer-acting ACE inhibitors cause less first-dose hypotension 
Furthermore the doses of both drugs that were used were higher than in present clinical practice. Giles et $a l^{19}$ found that the longer acting agent, lisinopril, caused a rise in serum creatinine in more patients than captopril. It has been suggested that the longer acting agents, such as enalapril and lisinopril, may be more likely to adversely affect renal function than captopril, which is short-acting, as they do not allow the renin-angiotensin system to recover between doses.

In our study, we used 'gold standard' methods to measure GFR, not just serum creatinine. There was a tendency for GFR to improve in patients taking captopril and deteriorate in those taking enalapril, although the differences between the drugs were not statistically significant. Significantly more patients on enalapril had more than a $10 \%$ fall in GFR compared with those on captopril. These findings are consistent with previous studies. However, since the baseline figures for GFR in the enalapril patients were higher than those on captopril, it is possible that the slightly larger numbers of patients showing a fall in GFR on enalapril could be seen as a regression towards the mean. This encouraging renal profile may have partly been due to using lower dosages of both ACE inhibitors. It may also have been because we only measured GFR after three months treatment, by which time improvement in cardiac function would have compensated for any deterioration in renal

The following centres participated in this study:

Queen Elizabeth Hospital, Birmingham

Dr C Haffner, Dr MJ Kendall, Sr D Hubscher

Southern General Hospital, Glasgow Dr D Stott, Dr MacDonald

Ninewells Hospital, Dundee

Prof AD Struthers, Dr JJF Belch, Dr A Bridges

Wrexham Park Hospital, Slough

Dr Blackwood, Dr

Gunawardena

Good Hope Hospital, Sutton Coldfield Dr S Davies function during the first week of treatment.

First-dose hypotension is a particularly important adverse event in the elderly. Hyponatraemia as an important risk factor for first-dose hypotension (30 times the risk if $\left.\mathrm{Na}^{+}<130 \mathrm{mmol} / \mathrm{l}\right) .{ }^{27}$ In elderly patients with stable chronic heart failure, the first dose of captopril produced an early $(1.5 \mathrm{~h})$ brief fall in blood pressure; the first dose of enalapril reduced blood pressure later $(4-10 \mathrm{~h})$ and for longer. ${ }^{28}$ Although the initiation of ACEinhibitor therapy caused large falls in systolic blood pressure in many patients, few had any associated symptoms. There was no significant difference between the ACE inhibitors in the magnitude of blood pressure reduction.

The fact that three patients taking enalapril had late onset symptomatic hypotension after three days of treatment which was noticed when they either fell or their mobility deteriorated indicates the importance of early

1 Giles TD. Enalapril in the treatment of congestive heart failure. I Cardiovasc Pharmacol 1990; 15 (suppl 3): S6-S10.

2 Wheeldon NM, MacDonald TM, Flucker CJ, McKendrick AD, McDevitt DG, Struthers AD. Echocardiography in chronic heart failure in the community. $Q \mathcal{F}$ Med 1993; 86: 17-23.

3 Massie BM, Conway M. Survival of patients with congestive heart failure: past present and future prospects. Circulation 1987; 75 (suppl IV): $11-19$.

4 Packer M. Cardiac failure: advances in the pathogenesis and treatment of heart failure. Curr Opin Cardiol 1989; 48 treatment

5 Captopril Multicentre Research Group. A placebo controlled trial of captopril in refractory chronic congestive hear failure. F Am Coll Cardiol 1983; 2: 755-63.

6 Cleland JG, Dargie HJ, Hodsman GF, et al. Captopril in heart failure: a double blind controlled trial. Br Heart $f$ 1984; 52: 530-5.

7 Captopril Digoxin Multicentre Research Group. Comparative effects of therapy with captopril and digoxin in patients with mild to moderate heart failure. $\mathcal{F} A M A 1988$ 259: 539-44.
Cardiac failure in the elderly

- ACE inhibitors, unlike other treatments, not only improve symptoms but also prolong life

- concerns of doctors centre on

- first dose hypotension

- possible adverse effects on renal function

- in clinical practice

- hypotension occurs after the first dose but symptomatic hypotension is uncommon

- short-term disturbances in renal function are often noted, in the long-term renal function is maintained and may improve

- elderly patients tolerate ACE inhibitors reasonably well

Box 4

review of patients who tolerate their first dose of ACE inhibitor and are then sent home. McLay et $a l^{29}$ found that some patients had a large fall in blood pressure after their fourth dose of captopril whereas they had only a small reduction in blood pressure after the first dose, suggesting that this adverse reaction can occur with both short- and long-acting drugs.

\section{Conclusion}

The most important and clinically relevant conclusion from this study was that both ACE inhibitors were well tolerated in elderly patients with chronic heart failure. There was no significant difference between their effects on mean GFR. However, there was an increased risk of deterioration in GFR in patients taking enalapril, although this could have been due to the higher initial value in the enalapril group. The first doses of drugs were well tolerated despite hypotension being common. The reasons for the late-onset hypotension observed in three patients are not entirely clear but clinicians should be aware that this may happen. Thus, the differences between the two ACE inhibitors were marginal. Captopril does offer the advantage that it may be easier to monitor patients for shorter periods of time after giving the first dose.

Thanks are due to Dr G Pover and Louise Hadley of Bristol-Myers Squibb Pharmaceuticals which generously supported this research project, and to $\mathrm{Dr} R$ Ferner, consultant toxicologist at Dudley Road Hospital, Birmingham, for his helpful comment.

8 CONSENSUS Study Group. Effects of enalapril on mortality in severe congestive heart failure. $N$ Engl f Med 1987; 316: 1429-35.

9 SOLVD investigators. Effect of enalapril on survival in patients with reduced left ventricular ejection fraction and congestive heart failure. $N$ Engl f Med 1991; 325: 293-302.

10 Pfeffer M, Braunwald E, Moye L, et al. Effect of captopril on mortality and morbidity in patients with left ventricular dysfunction after myocardial infarction. N Engl F Med 1992, 327: 669-77.

11 The Acute Infarction Ramipril Efficacy (AIRE) Study Investigators. Effect of ramipril on mortality and morbidity of survivors acute myocardial infarction with clinical evidence of heart failure. Lancet 1993; 342: 821-8.

12 Murphy P, Van der Cammen T, Malone-Lee J. Captopril in elderly patients with heart failure. $B M F$ 1986; 293: 239-40.

13 Impallomeni MG. Can captopril replace diuretics in the treatment of chronic failure in the elderly? Geriatr Cardiovasc Med 1988; 1: 215-9. 
14 Giles TD, Fisher MB, Rush JE. Lisinopril and captopril in the treatment of heart failure in older patients: comparison of long and short acting angiotensin converting enzyme inhibitors. Am f Med 1988; 85 (suppl 3B): 44-7.

15 Woodward MC, Warne RW, Brown RW. The effectiveness of captopril in the treatment of refractory congestive cardiac failure in the elderly. Aiust NZ $\mathcal{F}$ Med 1987; 17 (suppl 1): 110 (abstract).

16 Alicandri C, Boni E, Zaninelli A, Fariello R, Muiesan G. Captopril versus digoxin in young and old patients with heart failure. Eur $\mathcal{F}$ Clin Invest 1987; 17: A22.

17 O'Neill CJ, Bowes SG, Sullen CM, et al. Evaluation of the safety of enalapril in the treatment of heart failure in the very old. Eur $¥$ Clin Pharmacol 1988; 35: 143-9.

18 Packer M, Lee WH, Yushak M, Medina N. Comparison of captopril and enalapril in patients with severe CHF. $N$ Engl captopril and enalapril in pati

19 Giles TD, Katz R, Sullivan JM, et al. Short and long acting ACE inhibitors: a randomized trial of lisinopril versus ACE inhibitors: a randomized trial of lisinopril versus
captopril in the treatment of congestive heart failure. $\mathcal{f} \mathrm{Am}$ Coll Cardiol 1989; 13: 1240-7.

20 Struthers AD. The clinical pharmacology of ACE inhibitors in chronic heart failure. Pharmacol Ther 1992; 53: 187-97.

21 Waller DG, Keast CM, Fleming JM. Measurement of GFR with $99 \mathrm{mTCDTPA}$ : comparison with plasma clearance technique. F Nucl Med 1987; 28: 372-7.

22 Edgington ES. Randomization tests. In: Owen DB, ed. Statistics: textbook and monographs, Vol 31, New York: Marcel Dekker, 1980
23 Anon. Failure to treat heart failure, (editorial) Lancet 1992; 339: 278-9.

24 Cleland JC, Dargie HJ. Heart failure, renal function and angiotensin converting enzyme inhibition. Kidney Int 1987; 31 (suppl 20): 220-8.

25 Levine TB. Effect of angiotensin converting enzyme inhibition on filtration rate in the treatment of heart failure. Clin Ther 1980; 11: 495-501.

$26 \mathrm{Cohn} \mathrm{J.} \mathrm{Comparison} \mathrm{of} \mathrm{enalapril} \mathrm{with} \mathrm{hydrallazine-}$ isosorbide dinitrate in the treatment of chronic congestive heart failure. $N$ Engl f Med 1991; 325: 303-10.

27 Packer M, Lee WH, Kessler PD, et al. Identification of hyponatraemia as a risk factor for development of functional renal insufficiency during converting enzyme inhibition in revere chronic heart failure $f$ Am Coll Cardiol 1987; 10 s37-44.

28 MacFadyen RJ, Lees KR, Reid JL. Differences in first dose response to angiotensin converting enzyme inhibition in response to angiotensin converting enzyme inhibition in congestive heart failure: a

29 McLay JS, McMurray J, Bridges A, Struthers AD. Practical issues when initiating captopril therapy in chronic heart failure. What is the appropriate dose and how long should patients be observed? Eur Heart $\mathcal{F}$ 1992; 13: $1521-7$.

Arthur Dickson (Dickie) Wright (1897-1976) was born in Dublin, Ireland the third child of a medical student who worked in a bank by day. His father went into practice in Paddington and Dickie became a medical student at St Mary's Hospital. Still a medical student, he served in the 1914-18 War as a gunner on the Somme and at Ypres and as a balloonist in the Flying Corps. At the age of 26 he became professor of surgery in Singapore but returned to become, eventually, senior surgeon at St Mary's and at the Prince of Wales Hospitals. He was an outstanding surgeon and was at home operating on the abdomen, chest, heart and brain. It was said that he cut well, sewed well and his patients got well. He was a highly sought after-dinner speaker. At one evening debate he had to follow a dull talk by a renowned homeopathist. Dickson Wright compared homeopathy with the throwing of an aspirin tablet in the Thames at Dagenham and drinking the water at Westminister Bridge. He became President of numerous societies including the Hunterian, Harveian, Osler Club, and Medical Society of London. He died of a stroke on 6 January 1976. He was larger than life and passed into memorable legend.

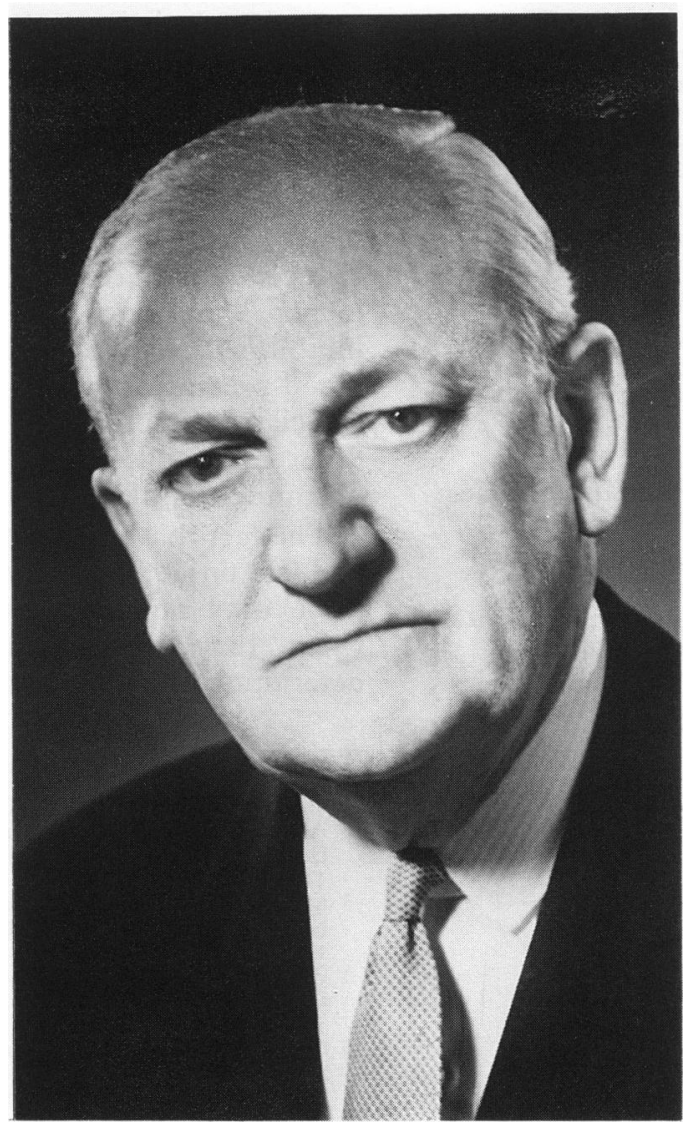

